\title{
Improvisation, Enaction, and Self-Assessment a
}

Dylan van der Schyff

The Oxford Handbook of Philosophical and Qualitative Assessment in Music Education

Edited by David J. Elliott, Marissa Silverman, and Gary E. McPherson

Print Publication Date: Sep 2019 Subject: Music, Music Education

Online Publication Date: Jul 2019 DOI: 10.1093/oxfordhb/9780190265182.013.15

\section{Abstract and Keywords}

This chapter explores the challenging question of curriculum and assessment for music improvisation pedagogy. It begins by offering a critical review of standard approaches to improvisation pedagogy, arguing that they often neglect the processes of discovery and collaboration that more open or "free" approaches afford. It then discusses the challenges that free improvisation poses to traditional modes of practice and assessment in music education. The chapter considers the argument that improvisation, in its fullest sense, cannot be taught and assessed according to standardized models; it is not something to be inculcated in students, but rather is a fundamental disposition that should be nurtured. This perspective is then developed in light of recent advances in enactive cognitive science, in which living cognition is explored as a fundamentally embodied, embedded, enactive, and extended (4E) phenomenon. The suggestion is made that because the ways living agents engage with these dimensions are not pre-given but rather reflect the adaptive processes associated with survival and well-being in contingent sociomaterial environments, there is a very strong sense in which cognition may be understood as an improvisational process even at the most fundamental levels. Following this, the chapter explores how a 4E cognition model might help guide curriculum development and offer a framework for forms of self-assessment involving collaborative processes of creative action and reflection. In conclusion, the chapter offers a few final thoughts drawn from existing musical communities and the author's experience as an improvising musician.

Keywords: music education, free improvisation, $4 \mathrm{E}$ cognition, self-assessment, creativity

(p. 319) EVERY human culture engages in activities that people recognize as musical. And in various ways, such behavior is often characterized by spontaneous acts of sound making. While these "improvised" expressions occur within melodic, rhythmic, sonic, harmonic, and social frameworks that evolve culturally, they also vitalize traditional practices keeping the music (and the culture) alive. Through improvisation the practitioner may explore his or her embeddedness in a given milieu, while simultaneously making unique contributions to the living enactment and transformation of that same sociocultural envi- 


\section{Improvisation, Enaction, and Self-Assessment}

ronment. And sometimes this may involve making radical breaks from established practice and ways of thinking and doing (Bailey, 1993; Borgo, 2007; Elliott, 1996; Lewis, 2004). Indeed, there is a strong sense in which improvisation may be seen as a meeting place for the present and the ancestral, the individual and the group, tradition and innovation. In many ways the phenomenon of musical improvisation may also be understood to reflect the adaptive and relational nature of human meaning and world making more generally. As Lee Higgins and Roger Mantie (2013) note, "improvisation is a distinctive way of being in and through music that reflects the fact that the act of living is largely improvisatory" (p. 38). This insight is echoed by thinkers such as Vijay Iyer (Miller \& Iyer, 2010) and Stephan Nachmanovitch (1990), who argue that there is no essential difference between human experience and improvisation, and George E. Lewis (2009a), who suggests that the human condition is the condition of improvisation.

However, although improvisation is central to most musicking (Small, 1998)—and may be an important characteristic of human cognition-it has been essentially eliminated from Western classical music practice ${ }^{1}$ and largely ignored in scholarship (Nettl, 1974). Keith Sawyer (2007) notes that although improvisation was common in European art music well into the nineteenth century,

\section{(p. 320)}

the current musical culture in Western countries-one in which a highly skilled instrumentalist may be completely incapable of improvising-is historically and culturally unique. Today, in Western cultures, improvisation is almost completely absent from the high art tradition and, consequently, is almost completely absent from the music education curriculum.

As a result, improvisation now "enjoys the curious distinction of being both the most widely practiced of musical activities and the least acknowledged and understood" (Bailey, 1993, p. ix).

This situation is beginning to change, however, and a growing number of scholars are exploring musical improvisation from a range of philosophical, psychological, historical, and cultural perspectives (Born, Lewis, \& Straw, 2017; Heble \& Caines, 2014; Lewis \& Piekut, 2016). Likewise, critically minded thinkers in music education have begun to develop approaches that place improvisation at the core of the curriculum (Sawyer, 2007; Heble \& Laver, 2016; Hickey, 2009). In doing so they argue that as a situated practice that embraces adaptivity, contingency, and the unexpected, improvisation challenges many standard ways of thinking about knowledge construction, meaning making, and cognition in general (Kanellopoulos, 2011). Indeed, it is often said that musical improvisation cannot be taught (see Borgo, 2005; Hickey, 2009). Nevertheless, people do learn how to do it. And most often such learning occurs collaboratively and outside of predetermined formal methods or institutional contexts (Green, 2008; Wright \& Kanellopoulos, 2010). It follows, then, that a nonreductive and open-ended exploration of improvisation may reveal new 
perspectives on teaching, learning, and assessment that could have profound implications for the future of education, musical or otherwise (Sawyer, 2007).

With such concerns in mind, this chapter develops a number of threads drawn from pedagogical theory and embodied cognition in an attempt to contribute to a better understanding of the meaning of improvisation for music education. I begin by considering a number of pedagogical perspectives on improvisation and examine the challenges they pose to taken-for-granted assumptions about teaching and assessment. Drawing on these ideas, I then develop the aforementioned insight regarding the deep continuity among improvisation, life, and cognition. Here I consider improvisation in the context of an alternative but increasingly influential enactive approach to mind (Varela, Thompson, \& Rosch, 1991; Stewart, Gapenne, \& Di Paolo, 2010; Thompson, 2007)-a perspective that I suggest allows us to explore the primacy of improvisation in a way not available through standard information-processing models of cognition. Following this, I consider how the " $4 \mathrm{E}$ " model associated with enactivism (which sees living cognition as essentially embodied, embedded, enactive, and extended) may provide a useful framework for developing self-reflective and collaborative ways of exploring and assessing improvisational experiences in music education. I conclude by offering suggestions for improvisational practice and assessment in pedagogical settings drawn from a number of existing musical communities and my own experience as a performer and educator.

I should make it clear that my goal is not to offer some kind of repeatable or fixed method for the assessment of improvisation in music. Rather, through a critical exploration (p. 321) of what improvisation entails I hope to draw out a general theoretical orientation that might aid educators and students in developing approaches that are relevant to their lives, goals, and shared experiences. As a result, I will not focus solely on assessment, but will also explore issues related to pedagogy and praxis.

\section{Improvisation and Music Education}

In recent decades a range of thinkers have begun to critically examine taken-for-granted attitudes about music and music education. For example, while the score and the composer continue to hold privileged places in Western music culture, this is increasingly problematized in association with a number of cultural and historical developments. These include, among other things, the rise of romantic notions of the elite composer-genius, the concert hall and the institutionalization of the classical cannon, mechanical reproduction and commodification, and the bureaucratic-capitalist cultural environment that characterizes modern life (DeNora, 1986; Goehr, 1992; Small, 1998; van der Schyff, 2015b). Some scholars have suggested that the dominant Eurocentric view of what "serious" music entails has exerted a colonizing (Bradley, 2012) influence on music education around the world-one that often obscures the rich improvisational characteristics of indigenous musical traditions in favor of the "gold standard" offered by the classical canon (Imada, 2012; Nettl, 1974, 1998). 


\section{Improvisation, Enaction, and Self-Assessment}

According to many writers, this perspective downplays the importance of situated and creative activities associated with nonclassical music-that is, playing by ear, improvisation, and the creation of original music (Rodriguez, 2004; Creech et al., 2008). As such, it does not encourage the development of unique ensembles and approaches to music-making that reflect the day-to-day lives of individuals, social groups, and indigenous or marginalized cultures. Therefore it is claimed that the standard focus on the reproduction and analysis of Western musical works tends to leave little space for the development of personhood, as well as the expression and exploration of difference and diversity that is so crucial for understanding and navigating the complex, heterogeneous world we live in in the twenty-first century (Elliott \& Silverman, 2015).

Notably, in recent years there has been a growing call for the (re)introduction of improvisation-not only for music education, but also for pedagogical theory and practice more generally (Campbell, 2009). For example, Sawyer (2003, 2006, 2007) sees the focus on "the composition" as a residue of industrial era thinking, in which, as with other aspects of life and work, the modes of production became isolated from each other. This, Sawyer (2007) argues, led to a situation in the musical domain in which performance and composition became two separate activities: "Where the creation of new music is almost exclusively associated with composers; and where a performers' primary role is to execute those compositions. In this division of labor, instrumentalists do not need to be capable of creating new music, nor do they need the correspondingly deeper conceptual understanding of music that underlies composition. [...] In our (p. 322) culture's stereotypical view, we do not think their creativity is of the same order as the composer who generates the score." Here, Sawyer $(2003,2007)$ develops comparisons with the "decontextualized and compartmentalized" industrial era approach to education, in which students are simply trained to memorize and reproduce existing knowledge, and they study and are tested essentially in isolation. Furthermore, Sawyer (2007) argues that we need to leave this "production line" approach behind as it tends to isolate and instrumentalize teachers and students, affording little practice in developing "the deeper conceptual understanding[s] and adaptive expertise that allow them to generate new knowledge."

To meet the latter concern, Sawyer $(2006,2007)$ draws on research associated with learning science, outlining four key and overlapping cognitive-pedagogical goals that reflect the creative possibilities of the human mind. These involve the development of deep conceptual understanding, in which facts and techniques are not simply learned for their own sake, but rather are explored within complex and evolving conceptual frameworks. Related to this is the advancement of integrated knowledge, which highlights the relational nature of knowledge building, in which understanding does not result from the possession of "compartmentalized knowledge," but rather emerges from the way knowledge is integrated in practice. Central to this process is the notion of adaptive expertise, which involves developing the ability to draw on previous experiences and skills in ways that are flexible, that adapt appropriately to the contingent demands of the moment. Finally, Sawyer (2007) considers the importance of collaborative skills, in which "unlike the hierarchical corporation of old, where everyone's job description was quite specific, the 
boundaries between each team member are fluid, and many tasks require the simultaneous and joint contributions of multiple experts to be successfully accomplished."

Importantly, these four pedagogical goals are also necessary requirements of effective musical improvisation. Indeed, improvising musicians must understand, integrate, and adapt a wide range of skills and knowledge. And often this is done in collaborative environments (Azzara, 2002; Monson, 1996; MacDonald, Wilson, \& Miell, 2011)—where outcomes are not pre-given, unforeseen challenges continually emerge and are met in various ways, and working relationships between people are not rigidly defined. Similarly, as Sawyer $(2006,2007)$ points out, the new environments for general education proposed by learning science explicitly embrace an improvisational attitude: "They place students in loosely structured environments, where they work together in a relatively unstructured, improvisational fashion. [...] In these learning environments, different student groups can develop different solutions to the same problem, which is exactly what you would expect if they were truly given the freedom to improvise" (2007).

In brief, it is argued that involving students in collaborative improvisational activities may help them not only develop new ways of engaging with music, but also open ways of thinking, doing, and being that are relevant across a range of domains. Here it is also important to note that such perspectives do not necessarily imply that the study and practice of classical music should be done away with. Rather, it is suggested that this field (and the composition and interpretation of notated music more generally) may be (p. 323) critically resituated within a richer understanding of what human musicality and creativity entails (Lawrence, 1978; Sawyer, 2007). ${ }^{2}$

\section{Teaching and the Question of "Improvisation"}

While there has indeed been a growing recognition of the importance of improvisation in music education in recent decades, the question of just how it should be introduced and developed continues to be debated. Some authors assert that while improvisation is important, the chief focus should remain on composition (Paynter, 1992). Others argue that improvisation should come first in music education, and that it should remain at the core of the music curriculum, with part reading and score analysis taking on an important but secondary role only later on in the educational process (Hickey, 2009; Sawyer, 2007). Perhaps more problematically, a growing number of writers suggest that by and large, the way improvisation is currently understood and practiced in music education does not always embrace the full possibilities of what it entails, and thus current curricula may not be able to meet the kinds of cognitive-creative potentials outlined here (Hickey, 2009).

To better understand such concerns, it may be useful to consider the shifting pedagogical attitudes toward improvisation that have developed over the last century. For example, some of the earliest research and literature on improvisation and music education in the United States emerged in the early and middle twentieth century (Coleman, 1922, 1927a, 1927b, 1939; Moorhead \& Pond, 1941/1978). These early studies embrace an open (and interdisciplinary) approach, in which pupils are free to develop their relationships to vari- 


\section{Improvisation, Enaction, and Self-Assessment}

ous instruments and each other in ways that are not strictly prescribed. As Gladys Evelyn Moorhead and Donald Pond (1941/1978) note: “To produce his own music a young child's first need, we find, is freedom-freedom to move about in pursuit of his own interests and purposes, and freedom to make the sounds appropriate to them" (p. 33). This research remained relatively marginalized, however, and it was not until the 1970s that "improvisation as a real learning outcome in American schools first appeared [...] mostly in the form of jazz improvisation, as jazz was beginning to be accepted as a legitimate music ensemble in public schools" (Hickey, 2009, p. 289; see also MENC, 1974). But this new approach to improvisation was not based in the free processes of discovery that characterized earlier research. Instead, improvisation is understood here as consisting of a set of (objective) skills, which are first to be acquired by the teacher and then passed on in a systematic fashion to students (e.g., Konowitz, 1973; Lasker, 1971; see also Pressing, 1988).

Generally speaking, these approaches tend to follow a linear schema, wherein the learner moves from one stage to the next in a controlled fashion. Often this begins with embellishing (or completing) existing melodies and musical phrases. This is followed by (p. 324) exposure to patterns (e.g., the licks or riffs that may be played over certain harmonic cadences), which students become adept at deploying in stylistically appropriate ways (e.g., Aebersold, 2000; Azzara \& Grunow, 2003; Baker, 1988; Coker, 1997; Gordon, 2003a). Such skills are then applied to solving larger musical problems (e.g., improvising through longer and more complex harmonic forms), which may be supplemented by transcriptions and imitating by ear. More open ways of improvising - if they are considered at all-are generally introduced (i.e., permitted) only once such skills have been acquired. Many jazz methods proceed in this way. Early music education approaches (e.g., Orff-Schulwerk) that claim to teach improvisation use similar linear frameworks to provide students with the appropriate "building blocks" to proceed through clearly defined stages of learning and assessment (see Abril, 2013).

Of course the assertion here is not that such technical forms of training are valueless. Learning to navigate musical compositions and genres-and understanding the theoretical frameworks (e.g., tonal harmony) by which they are constructed and analyzed-is extremely important. And practicing within defined parameters can help with the development of instrumental control and ensemble awareness. However, critics argue that improvisation involves much more than this (Borgo, 2005, 2007; Elliott, 1996; Hickey, 2009; Lewis, 2007). Indeed, it is suggested that the focus on a standardized and technically driven music improvisation pedagogy ignores the informal, exploratory, or "free" processes of discovery, collaboration, and adaptation that result in new situated forms of knowing and doing. It only asks students to understand preexisting knowledge and methods and (re)produce musical "products" that are deemed to be functional (or "correct") within such pre-given frameworks. As such, it is often assumed that students are necessarily subordinate to these frameworks and that their development must therefore be controlled -that is, that they are incapable of improvising "correctly" without supervised interventions. The possibility is rarely entertained that, given the appropriate environment and encouragement, students could (and will) adapt and transform such frameworks (and the 
skill sets and understandings that characterize them) and thus collectively develop new approaches (their own ways of musicking) that resonate with and express their individual and shared experiences in unique and sometimes unexpected ways. Researchers who explore "informal learning" have shown that it is just these kinds of collaborative and socially relevant processes-that is, the adaptive acquisition and development of skill and understanding through situated praxis-that characterize creative musical activity outside of formal contexts (Green, 2002, 2008; Musical Futures, 2008; O’Neill, 2014; Price, 2006; Wright \& Kanellopoulos, 2010).

In brief, it is argued that the "technicist" (Regelski, 2002) orientation of much formal music education tends to impose a reduced understanding of improvisation, which is assumed to consist of a set of "carefully prescribed technique[s] centered around tonal harmony and regular rhythms, but is devoid of both context and freedom" (Hickey, 2009, p. 290). In many ways this orientation reflects the same trends toward standardization associated with Sawyer's $(2003,2007)$ critique of industrial age thinking, in which the possibilities of human creativity and understanding are curtailed. Not surprisingly, however, this approach does make assessment a relatively straightforward affair, (p. 325) whereby a student's progress may be mapped against a list of externally imposed criteria (i.e., technical requirements). ${ }^{3}$

\section{Improvisation and the Question of "Teaching"}

I mentioned previously that the technical and product-driven approach to music education is often out of touch with how students frequently engage with music outside of school environments (Green, 2008). Equally problematic is the observation that the emerging pedagogy of improvisation in the last three decades of the twentieth century essentially ignored the living forms of improvisation that are actually occurring in the world at large-for example, the remarkable developments in jazz and free improvisation (Bailey, 1993; Berliner, 1994; Hickey, 2009, 2015; Lewis, 2007)_and how such developments intersect with cultural and critical perspectives, as well as a range of new technologies (Borgo, 2014; Borgo \& Kaiser, 2010; Born, Lewis, \& Straw, 2017). For example, most often large ensembles (big bands) dominate jazz education, in which improvisation fills out areas within a composition. However, such improvisations are almost always subservient to the framework imposed by the composer/arranger and generally involve sedimented hierarchies within the ensemble that interact in highly prescribed ways (e.g., soloistrhythm section). ${ }^{4}$ Moreover, as Michael Szekely (2012) argues, all of this reflects a trend toward codification, institutionalization, and commodification of the "language" of jazz, wherein the insistence that jazz should somehow be understood as "America's classical music" has resulted in a range of problematic assumptions. Thus, while there are many important skills that may be developed in more codified contexts, the resulting musical products often have little to do with the lives of the students who perform them, and the processes involved resonate only superficially with the collaborative and often highly idiosyncratic ways jazz musicians actually go about creating the music they do. 


\section{Improvisation, Enaction, and Self-Assessment}

Along these lines, a number of writers discuss improvisation not in terms of products or outcomes, but rather as an activity to be pursued for its own sake, ${ }^{5}$ often exploring the relevance of "free" or "nonidiomatic" improvisation for education (Borgo, 2007; Kanellopoulos, 2011; Wright \& Kanellopoulos, 2010). As Jacques Attali argues, free improvisation is "NOT undertaken for its exchange or use value. It is undertaken solely for the pleasure of the person who does it. [...] Such activity involves a radical rejection of the specialized roles (composer, performer, audience) that dominated all previous music" (1985/2006, p. 135). As Derek Bailey (1993) remarks, "Diversity is its most consistent characteristic. It has no stylistic or idiomatic commitment. It has no prescribed idiomatic sound. The characteristics of freely improvised music are established only by the sonicmusical identity of the person or persons playing it" (p. 83). Following these insights, Maude Hickey (2009) points out that "free improvisation is a form of (p. 326) improvisation that is ultimately the most open, non-rules bound, most learner directed, and, consequently, the least (if ever) approached in schools. It is not a free-for-all approach, as it requires attentive and sensitive listening to the environment and others involved. However, it is an improvisation that cannot be taught in the traditional sense, but experienced, facilitated, coached, and stimulated. [...] There is no right way to do it, and the process often requires more attention than the product" (p. 249). Indeed, because free improvisation highlights process, diversity, and the unique evolving relationships enacted between situated musical agents and their environments, it does not fit neatly into the standardized practices and prescribed outcomes that often characterize music curricula and assessment. Thus, as Ruth Wright and Panagiotis Kanellopoulos (2010) point out, "Improvisation becomes a means for unsettling dominant conceptions of music learning and for engaging with informal learning practices. Improvisation not only offers a way of active engagement with music, but also is situated [...] in an epistemology that does not regard knowledge as 'an accurate representation of a pre- existing reality' (Biesta \& Osberg, 2007, p. 16) but emphasizes the situatedness of knowledge construction as a form of creative socio-cultural praxis" (p. 82).

With such concerns in mind, a number of writers argue that improvisation, in its fullest sense, should not be understood as something to be inculcated, but rather as a kind of fundamental "disposition" that is to be nurtured and cultivated. This resonates with the insights mentioned previously regarding the improvisatory nature of life itself (more on this shortly). I suggest, therefore, that it should be this "improvisational disposition" that is initially recognized in music education so that students may develop a strong sense of their own creative potentials as self-making beings (Hickey, 2009). In other words, I argue that free improvising should be introduced first and encouraged throughout students' development. In this way, when technical and genre-specific concepts, practices, and cultural models are introduced to students, they may be encountered from the outset not as prescriptive, but rather as tools and possibilities for creative engagement with the (musical) worlds they co-enact.

This all leads back to the suggestion articulated by Hickey (2009): namely, that true improvisation may not be "teachable" within the rather narrow didactic (or "industrial") understanding of what education involves. Indeed, embracing this deeper understanding of

Page 8 of 32

PRINTED FROM OXFORD HANDBOOKS ONLINE (www.oxfordhandbooks.com). (C) Oxford University Press, 2018. All Rights Reserved. Under the terms of the licence agreement, an individual user may print out a PDF of a single chapter of a title in Oxford Handbooks Online for personal use (for details see Privacy Policy and Legal Notice). 
improvisation in pedagogical contexts demands a new and more complex understanding of the relationship between teachers and students, one that looks beyond rigid hierarchies and predetermined outcomes. Here the teacher must become more than simply a source of information, facts, and skills. Rather, he or she takes on the status of a facilitator and collaborator, providing the "scaffolding" (Lajoie, 2005; see also Elliott, 1995, pp. 278-80) for fertile creative environments to emerge and grow, in which students are encouraged to think critically, creatively, and collaboratively. From this perspective, teaching involves knowing when to play an active role and when to stand back and let the students take charge of their own learning, when to introduce a new cultural model or a conceptual/technical challenge, and when to let students explore without intervention (Green, 2008; Wright \& Kanellopoulos, 2010).

Of course, this all demands a good deal of critical reflection, creativity, adaptive flexibility, and the ability to engage with the needs of students (Laroche \& Kaddouch, 2015; (p. 327) O’Neill, 2010; Silverman, 2012). Indeed, to be effective, teachers cannot simply teach by rote; they must develop the ability to integrate and adapt their knowledge to the contingent demands and opportunities that arise in a given situation and perhaps even engage in the kinds of "subversive" teaching that looks outside of the standard curriculum (Elliott \& Silverman, 2015). Put simply, this means that teachers must actually embody the kinds of adaptive, creative, and collaborative learning that improvisation involves, so that by example they may reveal the kinds of processes they hope to encourage in their students.

I return to these concerns later in this chapter to explore possibilities for assessment and praxis. First, however, I further develop this idea of improvisation as a disposition, wherein "the act of living itself is largely improvisatory" (Higgins \& Mantie, 2013). Here I examine how emerging embodied or "enactive" approaches to cognition (Stewart et al., 2010; Thompson, 2007; Varela et al., 1991) may offer support for this insight and thus help to inform and ground new ways of thinking about improvisation, learning, and assessment.

\section{Cognition and Improvisation}

Until recently, our understanding of how the mind works was framed largely by a standard "information-processing" or "cognitivist" approach to cognition (Pinker, 2009). Put very simply, this approach understands the mind as analogous to a computing machine, in which "mind" is the software to the brain's hardware (Damasio, 1994). Here cognition is confined to nonconscious information processing in the head; it is understood to occur in a mechanistic or rule-based fashion that begins with the input of sense data and proceeds hierarchically through the development of evermore complex representations. This results, finally, in outputs-responses, behaviors, and "knowledge" - that correspond with a pre-given "world out there." In this view, we have no direct access to the world; our "experience" is of the representations (or "mental content") formed in the brain. Thus our "knowledge" of the world may be "assessed" in terms of the degree to which our mental content and resulting behaviors (outputs) correspond with a supposedly preexisting reali- 
ty (see Varela et al., 1991). It is also important to note that this approach does not see the body as playing a significant role in cognition as such; it simply provides the necessary biological scaffolding, "where brain and body are related but only in the sense that the former cannot survive without the life support of the latter" (Damasio, 1994, p. 48).

In many ways, this orientation has informed and reinforced the ways we think about and do music and education in the industrial and postindustrial eras. As a number of critical pedagogues have discussed, many modern approaches to education adopt a mechanistic or, indeed, a "banking" approach to education (Freire, 2000; Giroux, 2011). Again, this involves a rather depersonalized and mechanical input-output understanding of human cognition in which students are trained to perform and think (and are assessed) according to standardized practices and outcomes; as a result, the critical and (p. 328) creative potentials of teachers and students (and performers and listeners) are downplayed (see Kincheloe, 2003, 2008; van der Schyff, Schiavio, \& Elliott, 2016).

The cognitivist perspective has increasingly drawn criticism from thinkers across a range of disciplines who argue that it tends to reduce human cognition to an abstract "in-theskull" problem-solving process that largely ignores the exploratory, embodied, and creative nature of perception (Clarke, 2005; Kincheloe, 2003). These concerns are central to the interdisciplinary research program known as enactivism, which by contrast explores the mind as a fundamentally situated, embodied, and ecological phenomenon. ${ }^{6}$ The enactive approach does not reduce cognition to the representational recovery of a pre-given environment. Nor does it first understand the mind in mechanistic or computational terms. Rather, it explores cognition as originating in the basic biological processes of life itself-in the ways even the simplest organisms move, interact, and thus actively shape the environments they inhabit. Put simply, the enactive perspective sees mind and world (organism and environment) not as a fixed duality, but rather as continually co-arising in an improvised way-like "a path laid down in walking"7 (Varela et al., 1991). As such, it may help us to understand the deep continuity between cognition and improvisation and thus better account for (and lend support to) the conception of improvisation as disposition introduced in this chapter.

\section{Cognition as Embodied, Embedded, Enactive, Extended, and ... Improvised}

Despite its broad interests and its openness to being integrated-most notably as a theoretical framework-within a range of research programs (see Stewart et al., 2010), enactivism can be defined, broadly speaking, in two ways. First, it may be approached according to the basic qualities it identifies as characterizing cognition. Recently, these have been referred to as the "4Es," which describe the mind as fundamentally:

- Embodied: mind is an embodied phenomenon involving a deep relationship between action and perception (neural + extra-neural factors).

- Embedded: mind is situated within a contingent milieu.

Page 10 of 32

PRINTED FROM OXFORD HANDBOOKS ONLINE (www.oxfordhandbooks.com). (c) Oxford University Press, 2018. All Rights Reserved. Under the terms of the licence agreement, an individual user may print out a PDF of a single chapter of a title in Oxford Handbooks Online for personal use (for details see Privacy Policy and Legal Notice). 


\section{Improvisation, Enaction, and Self-Assessment}

- Enactive: mind involves a process of bringing forth or "enacting" a meaningful world.

- Extended: mind cannot be reduced to "in-the-skull" processes, but rather includes an "extended" cognitive ecology involving objects, technologies, sociocultural engagements, and other agents (organic + inorganic factors).

Second, the enactive perspective may also be distinguished by three overlapping principles that explain the quartet of characteristics just mentioned. The first of these, autopoiesis, describes how a living creature self-organizes its own existence in conjunction (p. 329) with the environment it emerges from and that sustains it, how it actively develops viable relationships within the contingent constraints and affordances of the given milieu it is embedded within according (most fundamentally) to its biological requirements. Importantly, living organisms are not seen as mere responders. Rather, they actively "reach out" to their environment to "seek out" and enact a world that is relevant to their continued well-being (Thompson, 2007). This involves an ongoing recursive or "circular" process of embodied interactivity and adaptivity that occurs, most primordially, through affectively motivated action as perception (Colombetti, 2014; Nöe, 2006; Schiavio, van der Schyff, Cespedes-Guevara, \& Reybrouck, 2016).

Such embodied processes are central to the second principle, sense making, which concerns the active ways living creatures disclose unique worlds of meaning that are informed and transformed by their interactions with every kind of otherness they encounter (Ihde, 1977; van der Schyff, 2015b). Indeed, while an organism may be differentiated by the bounded metabolic, self-regulative processes associated with the living body and its "inner" milieu, the same organism (if it is to remain a living individual) must also simultaneously maintain the dynamic organism-environment interactivity that allows it to make sense of its world in relation to its intrinsic needs. Thus, living cognition, mind, "identity," and "self" are necessarily relational and thus extended phenomena at the most primordial levels (McGann, De Jaegher, \& Di Paolo, 2013; Weber \& Varela, 2002).

This brings us to the third principle, autonomy, which describes how an organism's world and the "meanings" that arise from it are not externally imposed, but emerge through unique histories of interactivity with the environment (Di Paolo, 2005). This is to say that unlike computing machines-which require external entities (i.e., humans) to provide inputs and give meaning to their outputs-living cognitive systems actively and autonomously participate in the construction of their own lifeworlds (Varela et al., 1991). An important further consequence of this is that "information," "knowledge," and "meaning" can no longer be reduced to pre-given features of an external environment. Rather, they are seen as ontogenic - that is, as growing from the relevant relationships and valences that emerge as a dynamic organism-environment system constitutes a lifeworld (Oyama, 2000; Thompson, 2007). Along these lines, Varela and colleagues (1991) write that living cognition is based in the adaptive and embodied learning processes that enable not simply knowledge of "this" or "that," but rather "knowing how to negotiate our way through a world that is not fixed and pre-given but that is continually shaped by the types of actions in which we engage" (p. 144). With such insights in mind, I suggest that there is a 
very strong sense in which the enactive perspective reveals living cognition to be fundamentally improvisational. ${ }^{8}$

In recent years the enactive approach has been developed across a range of human activity and experience, including the field of social cognition. This has resulted in interesting new dimensions to the enactive perspective, including the notions of participatory sense making and relational autonomy (De Jaegher, 2013; De Jaegher \& Di Paolo, 2007). These concepts have been advanced, for example, in the context of the prelinguistic and embodied modes of communication and understanding that occur between infants and (p. 330) primary caregivers. Importantly, such basic social activity is no longer understood simply in terms of imitation or "hardwired" responses. Rather, infants are observed to play active roles in shaping the relationship by developing a repertoire of utterances and bodily movements that facilitate the enactment of a unique shared ecology of meaning (Krueger, 2013; Reddy, Markova, \& Wallot, 2013; Service, 1984). Again, this may be understood as continuous with the adaptive and improvisational character of living cognition more generally. It also expresses the relational conception of autonomy just mentioned, wherein "the self" cannot be reduced to some kind of fixed status, but rather is seen as an ongoing $4 \mathrm{E}$ process of (improvised) social and cultural enaction.

Moreover, a growing number of scholars are exploring the importance of musicality for such fundamental intersubjective forms of self and world making, including the primary forms of communicative movement and sound making just discussed (Krueger, 2014; Trevarthern, 2002; van der Schyff, 2015a). Indeed, musicality, broadly understood, is increasingly seen not simply as a cultural (pleasure) technology (Pinker, 2009), but rather as a "primordial, empathic, and embodied sense-making capacity that plays a central role in how we enact the personal and socio-cultural worlds we inhabit" (van der Schyff et al., 2016, p. 83). From this perspective improvisation and musicality go hand in hand as essential aspects of the human mind.

\section{Improvisation and Assessment}

As I discussed at the outset of the chapter, musical improvisation often occurs within social and cultural contexts (Azzara, 2002; Hickey, 2002). Such contexts are characterized, with varying degrees of specificity, by certain historically enacted ways of doing and knowing - culturally sedimented techniques and understandings that allow a given music to be identified with a place, time, or social milieu. With this in mind, there are certain aspects of improvisation that can be seen as correlating with existing standards and that can be assessed more or less "objectively." ${ }^{9}$ For example, within current modes of improvisation training, a teacher can assess knowledge of a given scale by asking a student to improvise a melody with it and by deducting a mark for every wrong note played. Likewise, the teacher could "test" a student's ability to play by ear by asking him or her to repeat melodic, harmonic, and rhythmic passages that are played or by getting the student to "outline" a set of chord changes, choosing from a given set of genre-based patterns and scales. 
These examples are relatively easy to assess and reflect current modes of training that characterize improvisation pedagogy. However, as I have noted, we must be careful not to let our understanding of music, education, and assessment be limited to those aspects that are simply in line with "national music standards" or reductionist and/or false concepts of what improvisation and assessment entail. In other words, I argue that while such technical forms of learning and assessment are important, they need to be decentered and take their place as one aspect of more open-ended, adaptive, and (p. 331) collaborative learning environments that embrace the concept of improvisation as disposition. But what new approaches to assessment might accompany the richer models of cognition, improvisation, and music education I have explored here? And what kinds of activities might be associated with them? What we are looking for, of course, is not simply another "method." Rather, what is needed is an open-ended framework for thought and action that may be developed by teachers and students as an ongoing project.

As I discuss next, a 4E cognition approach offers a way of decentering the "isolationist," "technically driven," and externally imposed forms of assessment associated with "industrial thinking" (see Sawyer, 2007). From this perspective "self-assessment" involves developing a deepened awareness of the reciprocity of the personal and collective processes that contribute to the development of a unique musical-cognitive ecology. Here "self" may refer both to the individual and to the shared reflective capacities of the ensemble or class as a whole. As such, this framework may better suit the kinds of contingent, collaborative, and open-ended forms of self-assessment that more complete improvisation pedagogy requires.

\section{Es and an I ... or Improvisation as Self-Assess- ment}

I suggest that if the $4 \mathrm{Es}$ can be used to describe the fundamentally improvisatory nature of living minds, characteristics of the $4 \mathrm{E}$ model can also be used to guide an approach to assessment and praxis that applies the concept of improvisation as disposition. While such forms of assessment will not exclude the technical or skills-based aspects of music making, they will necessarily be more concerned with reflecting and fostering the kinds of creative potentials and collaborative environments described previously (Sawyer, 2007; van der Schyff et al., 2016). This will involve encouraging students to be attentive to and reflect on how relationships form and develop with the people (ensemble mates), things (instruments), and places that constitute their reality; how their "selves" extend into the environment and play a role in constituting the lives of others; and how their sense of musical identity is continuously transformed through the activities of their peers. This reflects the relational conception of autonomy that I explored previously-one that goes far beyond the Enlightenment notion of "a lone individual merely extending [his or her] cognitive reach" (Urban, 2014, p. 4) toward a vision of selfhood as a communal project (Benson, 2001). 


\section{Improvisation, Enaction, and Self-Assessment}

Of course, such processes cannot be assessed simplistically and objectively, but rather require an open, cooperative dialogical approach that involves shared processes of action and critical reflection. Praxis and assessment should be understood as continuously guiding one another in a reciprocal fashion that reflects the biocognitive principles of autopoiesis and participatory sense making. From this perspective, "goals" and "outcomes" are not simply pre-given criteria, but possibilities that emerge from the needs, (p. 332) desires, and relevant self-assessments of the individual and group as they evolve dynamically. Thus, while the best way to begin improvisation in educational contexts may be, as Lewis suggests (see Borgo, 2005), to simply "throw" students directly into doing it, teachers must also be able to help students begin to critically examine and share the experiences that result and through such forms of self-assessment help students recognize the problems they wish to overcome, as well as open new possibilities to be developed.

With this in mind, students may be encouraged to engage in open-ended explorations of their relationship with their instrument(s) and to bring their discoveries to the ensemble. This will necessarily involve self-assessing the deeply embodied aspects of improvisation and instrumental practice (Berkowitz, 2010; Iyer, 2002, 2008). It will also include examining how the "resistance of the instrument" (Cochrane, 2013) plays a role in shaping the kinds of music one makes, as well as exploring the kinds of complex dynamics and embodied feedback loops that occur among the performer, instrument, acoustic environment, and other performers (Biasutti \& Frezza, 2009; Borgo, 2005; Pressing, 1998; Walton, Richardson, Langland-Hassan, \& Chemero, 2015). ${ }^{10}$

Central to such reflective processes will be developing in-the-moment assessments of shifting bodily-instrument-environment relationships and a growing awareness of the kinds of cross-modal, emotional-affective, self-regulatory, and "flow" experiences that characterize and motivate the improvising process (Csikszentmihalyi \& Rich, 1997; Johnson, 2007; McPherson, Lopez-Gonzalez, Rankin, \& Limb, 2014; Wopereis, Stoyanov, Kirschner, \& Van Merriënboer, 2013). Here the development of a "phenomenological attitude" will also be important (see Schiavio, this volume; van der Schyff, 2016). Indeed, as a number of authors have demonstrated, phenomenology offers a coherent means of analyzing and discussing first-person experience and is thus highly useful in musical contexts (Clifton, 1983; Ferrera, 1984, 1991; Ihde, 1976; Krueger, 2011; Roholt, 2014; Sudnow, 1978). Along these lines, the introduction of mindful awareness and meditation, as well as aspects of the Alexander technique, may also be very useful in developing such direct, embodied forms of self-assessment (Biswas, 2012; Sarath, 2013; van der Schyff, 2015a).

Teachers should also recognize that students do not come to musical improvisation as detached and decontextualized onlookers, as "blank slates." Rather, they are already embedded within a milieu that has developed historically. However, as previously discussed, the enactive perspective does not conceptualize the cognitive activity of people as simply determined by their environments; -rather, we actively shape the cognitive ecologies we inhabit, and mind and world stand in a circular, co-emergent relationship to each other (Varela et al., 1991). Therefore, students and teachers should also be encouraged to critically examine the social, cultural, and gendered worlds they participate in, as well as the 
musical-sonic spaces they "live through," and to reach out to the worlds of others through empathy, action, and imagination (Greene, 1995; Silverman, 2012). In this way, students may gain a better understanding of the world in which they find themselves. In doing so, key aspects may be "put into play," forming material for improvisations and the enactment of new relationships.

(p. 333) Such processes are likely to highlight the autonomous activities of individuals in the critical assessment of the (musical) worlds they inhabit and enact. At the same time, they will also encourage participants to embrace the collaborative possibilities of the ensemble. At advanced levels, this will involve (1) developing highly nuanced understandings of, and the ability to deconstruct, a wide range of existing musical practices, styles and techniques; (2) advancing deeper understandings of the relational nature of sound, ${ }^{11}$ movement, and space (Ihde, 1977); (3) developing ways of musicking that are unique to the individual and group; and (4) gaining the ability to reflect and (collaboratively) self-assess across multiple timescales (e.g., reflecting in action and reflecting on action; Schön, 1983).

With all of this in mind, a 4E framework for individual and collaborative forms of self-assessment asks students and teachers to consider questions such as the following:

- Embodied: What new instrumental challenges have emerged and what new body-instrument relationships and understandings have developed in the process of meeting them?

- Embedded: How have our musical activities explored and developed our understandings of the broader physical, sonic, historical, social, cultural, and gendered world(s) we live in as individuals and social groups? What roles does the sociocultural environment play in shaping the ways we improvise?

- Enactive: What new meanings have we opened up through our music making? What new relationships have emerged? And how have they transformed the ways we engage with the world musically, sonically, socially, emotionally, and so on?

- Extended: In what ways have my creative possibilities been enhanced or made possible through my interactions with coperformers, technologies, and other nonorganic ecological factors? And how have I helped to facilitate the creative development of others?

As I have suggested, the 4Es may be juxtaposed with the four-part criteria that Sawyer (2007) lays out (see previous discussion) in relation to learning science. In this way, a $4 \mathrm{E}$ approach may offer ways for students and teachers to collectively assess to what degree their activities have met such potentials and what new levels of understanding and activity have emerged as possible goals. And of course, these categories may also provide a starting place for more explicitly critical forms of assessment-that is, recognizing what kinds of behaviors and conditions might hinder creative development. 


\section{Improvisation, Enaction, and Self-Assessment}

Again, such understandings can only be properly developed, discussed, and assessed through the kinds of active, adaptive, and integrative praxis associated with a critically engaged approach to improvisation-that is, where practice and self-assessment become part of the same ongoing process. Indeed, the focus here is not simply on the products of training, but rather on assessing the process of creative development as it happens in an ongoing way (Dewey, 1997; Tarasti, 1993). And so, for example, while students might indeed be asked to self-assess a performance they have given according to various criteria, many of these criteria will have emerged through the reflective-creative processes of (p. 334) the students themselves. Here, assessment is framed less by externally driven standards and more by issues relevant to the development of the class (ensemble) itself as an autonomous, self-making system in its own right. ${ }^{12}$

The kinds of collaborative reflective processes a $4 \mathrm{E}$ improvisation pedagogy requires may also draw on (and help develop) the distinction between "authentic" and "inauthentic" forms of assessment-that is, the critical and reflective (self)assessment that is concerned with creative, contextual, and process-based learning, as opposed to the depersonalized, isolationist, and technically driven approaches associated with objectivist or standardized forms of assessment (see Weil, 2001). Importantly, a range of possibilities already exists for such "authentic" or "formative" types of assessment, including, for example, "foliobased" approaches. Here reflections and ideas, teacher-student and student-student interviews, descriptions and critiques of class activities, practice diaries, listening-viewing logs, performance reviews, the results of collaborative and self-directed research projects, and more may be collected and used to further enhance class dialogue (Elliott \& Silverman, 2015; Gardner, 1991). And indeed, such materials could be organized and discussed according to the $4 \mathrm{E}$ framework presented here. Moreover, thanks to developments in digital technology such "process folios" may also be easily supplemented with video and audio recordings. ${ }^{13}$ Likewise, previously difficult to acquire documentary films and performance footage of improvising musicians are now readily available online. These offer a range of real-world examples for students to consider. In this way, the process folio itself may be understood as a kind of bricolage (Kincheloe \& Berry, 2004) - a creative and critical pedagogical project in which material and ideas are collected, organized, and expressed in various ways that contribute to the development of the student and the class or ensemble.

\section{Conclusion: Toward Praxis}

While the enactive approach to improvisation explained here does not offer a fixed method of assessment, it nevertheless resonates with a rich pool of existing knowledge that informs possibilities for integrating creative practice, reflection, and self-assessment. Indeed, this orientation aligns most closely with ongoing research and theory associated with critical, "post-formal," and praxial approaches to education (Bowman, 2004; Kincheloe, Steinberg, \& Villaverde, 1999; Kincheloe, 2003; Elliott \& Silverman, 2015). It also encourages teachers and students to reach out to experienced improvisers, and to improvising communities and cultures, to explore living, real-world models (Bailey, 1993; Berliner, 


\section{Improvisation, Enaction, and Self-Assessment}

1994; Borgo, 2007; Lewis, 2009a; Monson, 1996). ${ }^{14}$ In the process, a wide range of possibilities may be discovered that are closely connected with the many concerns and insights discussed in this chapter.

Consider, for example, the free jazz and free improvisation movements that developed in the 1960s in America and Europe, respectively. Both produced a range of unique ensembles, performers, and creative communities, and both were in many ways politically (p. 335) charged. Free jazz strove to spiritually transform an oppressive and racist society in the United States (Monson, 2007), and free improvisation took on, among other things, the bourgeois capitalist-consumerist culture that characterized postwar European society (Borgo, 2005; Lewis, 2004, 2007). Many of the artists involved in both movements developed highly original approaches to their instruments, as well as ensembles that expanded understandings of what "music" can entail. Today, a range of texts, recordings, and films document these artists. These will be useful to students and educators in reflecting on their own relationships to music and culture (Bailey, 1993; Corbett, 2016; Lewis, 2009b; Litweiler, 1990; Toop, 2016; Watson, 2013; Whitehead, 2000; Stevens, 1984).

Excellent examples of communities of improvisers are Chicago's Association for the Advancement of Creative Musicians (AACM) and St. Louis's Black Artists Group (BAG) (see Lewis, 2009b). These organizations emerged to support important but highly marginalized communities of African American improvising musicians and to encourage creative musical practices that reflect the lived experiences and creative possibilities associated with black culture more generally. Importantly, in these communities the idea of culture and the individual identities that constitute it are not seen as pre-given, and the kinds of musical activities that these artists engage in are not strictly prescribed. Rather, culture and identity involve fluid, improvised processes in which various musical, mythological, historical, social, and sonic relationships are deconstructed and reconstructed. Individuals are encouraged to develop their own approaches to music making, which continually draw on, inform, and transform both the ensembles and the broader cultures they participate in.

Readers may wish to explore the Art Ensemble of Chicago (the AACM's "flagship" ensemble) and the ways it integrates and adapts "Great Black Music, Ancient to Future," as well as the members' individual perspectives on sound making and musical form. Another important example may be found in the music of the "Downtown" scene that emerged in New York City in the 1980s. These musicians explored a range of new approaches that often involved improvising with genre itself. Here, otherwise disparate types of music were juxtaposed, and musicians from diverse backgrounds were thrown into performances together. One important development of this community is the "game pieces" and improvised "conductions" associated with John Zorn (2004) and Butch Morris (Monga, 2012), respectively. ${ }^{15}$

Communities of creative musicians such as these offer useful models for those wishing to gain a better understanding of what improvising praxis entails in living contexts (see also Stevens, 2007). In the course of my career as an improvising musician, I have been fortu- 


\section{Improvisation, Enaction, and Self-Assessment}

nate to work with and learn from such artists. And in my teaching I have developed a number of activities and approaches informed by these experiences. For example, a "game piece" like Zorn's "Cobra" offers an excellent framework for exploring basic aspects of improvisation in pedagogical contexts. Put very simply, the game consists of a series of "prompts"-open frameworks for improvising within certain parameters that include memory, different ensemble groupings, dynamics, and so on. The ensemble members are required to develop their own strategies and material for effectively engaging with such prompts, which are initiated in various ways by the ensemble itself through a (p. 336) system of hand gestures (Brackett, 2008). While the complete game is very complex, it can be simplified for beginning improvisers. Moreover, "Cobra" does not require specific instrumentation or knowledge of a specific style of music; all instruments and backgrounds are welcome. Most important is that the game is enjoyable, and it affords a coherent but nevertheless open framework for participants to explore and discuss basic aspects of improvisation. ${ }^{16}$

Another activity involves a process I sometimes call "modular composition." It is inspired by the range of improvising communities discussed previously and was developed collaboratively with improvising ensembles in Europe and Vancouver, Canada. It involves getting participants to research and bring to the ensemble (among other things) forms, melodies, chord structures, rhythms, field recordings, new and old technologies, other media, new instrumental techniques, and sound-making possibilities, as well as concepts derived from their listening and reading. The material is then developed and given forms by the ensemble through an improvisational, exploratory process in which it is integrated, juxtaposed, and adapted in various ways (bricolage). This can result in fixed forms, wherein the musicians eventually improvise within and against an overarching structure they have developed collectively, or it can involve a mobile form, in which the various materials and ideas are cued and structured by the ensemble members in real time and in accordance with the flow of the music. The way such collaborative processes develop over time (i.e., through experimentation, negotiation, self-assessment, and the adaptive development of techniques and embodied understandings) can lead to distinct ensemble approaches and the enactment of strong musical identities and extended musical communities.

The wide range of concerns, ideas, and possibilities I have discussed in this chapter are intended to inspire richer and more open-ended approaches to improvisation pedagogy, curriculum, and assessment. In the end, however, it is up to educators themselves to engage in the kinds of ongoing critical reflection that will help them decide how to develop and address these issues in praxis. With this in mind, I hope that in the years to come a diverse range of new accounts will emerge about how improvisation may be implemented and assessed in pedagogical contexts. Moreover, it will be very interesting to see how such accounts align with the growing body of theory and research that explores the musical mind as an embodied, enactive, or 4E phenomenon (Borgo, 2005; Krueger, 2011a, 2011b, 2014; Matyja \& Schiavio, 2013; Reybrouck, 2001, 2005, 2006; Schiavio et al., 2016; Silverman, 2012; van der Schyff, 2015a, 2015b). 


\section{Improvisation, Enaction, and Self-Assessment}

Finally, although free improvisation remains a marginalized practice, it has nevertheless spread around the globe. Today most urban centers have an improvised music scene, where artists from diverse backgrounds collaborate and develop new approaches to music and sound making. Likewise, many contemporary communities are constituted by a range of indigenous and immigrant subcultures that engage in more traditional forms of musical improvisation. So if they are willing to search, educators and students may find substantial living resources of improvised music(s) in creative musical communities close to home.

\section{(p. 337) Acknowledgments}

Many thanks to Andrea Schiavio, Susan O'Neill, and David Borgo for their helpful comments on early drafts of this chapter. This work was supported by the Social Sciences and Humanities Research Council of Canada.

\section{References}

Abril, C. (2013). Critical issues in Orff Schulwerk. In C. Wang (Ed.), Orff Schulwerk: Reflections and directions (pp. 11-24). Chicago: GIA Publications.

Aebersold, J. (2000). The II/V7/I progression. Vol. 3, A new approach to jazz improvisation. New Albany, IN: Jamey Aebersold.

Attali, J. (1985/2006). Noise: The political economy of music. Minneapolis: University of Minnesota Press.

Azzara, C. D. (2002). Improvisation. In R. Colwell \& C. Richardson (Eds.), New handbook of research in music teaching and learning (pp. 171-87). Oxford: Oxford University Press.

Azzara, C. D., \& Grunow, R. F. (2003). Developing musicianship through improvisation. Chicago: GIA Publications.

Bailey, D. (1993). Improvisation: Its nature and practice in music. New York: DaCapo Press.

Baker, D. (1988). Jazz improvisation: A comprehensive method for all musicians. Van Nuys, CA: Alfred Publishing.

Benson, C. (2001). The cultural psychology of self: Place, morality, and art in human worlds. London: Routledge.

(p. 339) Berkowitz, A. (2010). The improvising mind. Oxford: Oxford University Press.

Berliner, P. (1994). Thinking jazz: The infinite art of improvisation. Chicago: University of Chicago Press. 
Biasutti, M. (2015). Pedagogical applications of cognitive research on musical improvisation. Frontiers in Psychology, 6, 614. doi:10.3389/fpsyg.2015.00614

Biasutti, M., \& Frezza, L. (2009). The dimensions of music improvisation. Creativity Research Journal, 21(2-3), 232-42.

Biesta, G., \& Osberg, D. (2007). Beyond re/presentation: A case for updating the epistemology of schooling. Interchange, 38(1), 15-29.

Biswas, A. (2011). The music of what happens: Mind meditation and music as movement. In D. Clarke \& E. Clarke (Eds.), Music and consciousness: Philosophical, psychological, and cultural perspectives (pp. 95-110). Oxford: Oxford University Press.

Borgo, D. (2005). Sync or swarm: Improvising music in a complex age. New York: Continuum.

Borgo, D. (2007). Free jazz in the classroom: An ecological approach to music education. Jazz Perspectives, 1(1), 61-88.

Borgo, D. (2014). Ghost in the music, or the perspective of an improvising ant. In G. E. Lewis \& B. Piekut (Eds.), The Oxford handbook of critical improvisation studies (Vol. 1) [Online]. New York: Oxford University Press.

Borgo, D., \& Kaiser, J. (2010, July 1-3). Configurin(g) KaiBorg: Interactivity, ideology, and agency in electro-acoustic improvised music. Proceedings of the International Conference Beyond the Centres: Musical Avant-Gardes Since 1950. Thessaloniki, Greece. http:// btc.web.auth.gr/

Born, G., Lewis, E., \& Straw, W. (Eds.). (2017). Improvisation and social aesthetics. Durham, NC: Duke University Press.

Bowman, W. (2004). Cognition and the body: Perspectives from music education. In L. Bresler (Ed.), Knowing bodies, moving minds: Toward embodied teaching and learning (pp. 29-50). Dordrecht, The Netherlands: Kluwer Academic Press.

Brackett, J. (2008). John Zorn: Tradition and transgression. Bloomington: Indiana University Press.

Bradley, D. (2012). Good for what, good for whom? Decolonizing music education philosophies. In W. Bowman \& A. L. Frega (Eds.), The handbook of philosophy in music education (pp. 409-33). New York: Oxford University Press.

Burnard, P. (2000). How children ascribe meaning to improvisation and composition: Rethinking pedagogy in music education. Music Education Research, 2(1), 7-23.

Campbell, P. S. (2009). Learning to improvise music, improvising to learn. In G. Solis \& B. Nettl (Eds.), Musical improvisation: Art, education, and society (pp. 119-42). Urbana: University of Illinois Press. 
Canonne, C., \& Garnier, N. B. (2012). Cognition and segmentation in collective free improvisation: An exploratory study. Proceedings of the 12th International Conference on Music Perception and Cognition and 8th Triennial Conference of the European Society for the Cognitive Sciences of Music, 197-204, http://icmpc-escom2012.web.auth.gr.

Clarke, E. F. (2005). Ways of listening: An ecological approach to the perception of musical meaning. Oxford: Oxford University Press.

Clifton, T. (1983). Music as heard: A study in applied phenomenology. New Haven, CT: Yale University Press.

Cochrane, T. (2013). On the resistance of the instrument. In T. Cochrane, B. Fantini, \& K. R. Scherer (Eds.), The emotional power of music: Multidisciplinary perspectives on musical arousal, expression and social control (pp. 75-84). Oxford: Oxford University Press.

(p. 340) Coker, J. (1997). Elements of the jazz language for the developing improviser. Miami, FL: Alfred Publishing.

Coleman, S. N. (1922). Creative music for children: A plan of training based on the natural evolution of music, including the making and playing of instruments, dancing-singingpoetry. New York: G. P. Putnam's sons.

Coleman, S. N. (1927a). Creative music for schools: Suggestions to teachers to be used in connection with first steps in playing and composing. New York: The John Day Company.

Coleman, S. N. (1927b). First steps in playing and composing: A music book for children. New York: The Lincoln School.

Coleman, S. N. (1939). Creative music in the home: Music, stories, how to make instruments, how to play them, and many tunes to play. New York: The John Day Company.

Colombetti, G. (2014). The feeling body: Affective science meets the enactive mind. Cambridge, MA: MIT Press.

Corbett, J. (2016). A listener's guide to free improvisation. Chicago: University of Chicago Press.

Creech, A., Papageorgi, I., Duffy, C., Morton, F., Hadden, E., Potter, J., ... Welch, G. (2008). Investigating musical performance: Commonality and diversity among classical and nonclassical musicians. Music Education Research, 10(2), 215-34.

Csikszentmihalyi, M., \& Rich, G. (1997). Musical improvisation: A systems approach. In K. R. Sawyer (Ed.), Creativity in performance (pp. 43-66). Greenwich, CT: Ablex.

Damasio, A. (1994). Descartes' error: Emotion, reason, and the human brain. New York: Putnam.

De Jaegher, H. (2013). Rigid and fluid interactions with institutions. Cognitive Systems Research, 25-26(0), 19-25. 
De Jaegher, H., \& Di Paolo, E. A. (2007). Participatory sense-making: An enactive approach to social cognition. Phenomenology and the Cognitive Sciences, 6(4), 485-507.

DeNora, T. (1986). How is extra-musical meaning possible? Music as a place and space for "work." Sociological Theory, 4(1), 84-94.

Desjarlais, M., \& Smith, P. (2011). A comparative analysis of refection and self-assessment. International Journal of Process Education, 3(1), 3-18.

Dewey, J. (1997). Democracy and education. New York: Simon \& Schuster.

Di Paolo, E. A. (2005). Autopoiesis, adaptivity, teleology, agency. Phenomenology and the Cognitive Sciences, 4(4), 429-52.

Elliott, D. J. (1995). Music matters: A new philosophy of music education. New York: Oxford University Press.

Elliott, D. J. (1996). Improvisation and jazz: Implications for international practice, International Journal of Music Education, 26(1), 3-13.

Elliott, D. J., \& Silverman, M. (2015). Music matters: A philosophy of music education (2nd ed.). New York: Oxford University Press.

Ferrara, L. (1984). Phenomenology as a tool for musical analysis. Musical Quarterly, 70(3), 355-73.

Ferrara, L. (1991). Philosophy and the analysis of music: Bridges to musical sound, form and reference. Westport, CT: Greenwood Press.

Freire, P. (2000). Pedagogy of the oppressed (30th anniv. ed.). New York: Bloomsbury Academic.

Gardner, H. (1991). The unschooled mind: How children think and how schools should teach. New York: Basic Books.

Giroux, H. (2011). On critical pedagogy. New York: Continuum.

Goehr, L. (1992). The imaginary museum of musical works: An essay in the philosophy of music. Oxford: Clarendon Press.

(p. 341) Gordon, E. E. (2003a). Improvisation in the music classroom. Sequential learning. Chicago: GIA Publications.

Gordon, E. E. (2003b). Learning sequences in music: Skill, content, and patterns; A music learning theory. Chicago: GIA Publications, Inc.

Green, L. (2002). How popular musicians learn: A way ahead for music education. London: Ashgate. 


\section{Improvisation, Enaction, and Self-Assessment}

Green, L. (2008). Music, informal learning and the school: A new classroom pedagogy. London: Ashgate.

Greene, M. (1995). Releasing the imagination. San Francisco, CA: Jossey-Bass.

Heble, A., \& Caines, R. (Eds.). (2014). The improvisation studies reader: Spontaneous acts. London: Routledge.

Heble, A., \& Laver, M. (Eds.). (2016). Improvisation and music education: Beyond the classroom. London: Routledge.

Hickey, M. (2002). Creativity research in music, visual art, theatre and dance. In R. Colwell \& C. Richardson (Eds.), The new handbook of research on music teaching and learning (pp. 398-415). New York: Oxford University Press.

Hickey, M. (2009). Can improvisation be "taught"? A call for free improvisation in our schools. International Journal of Music Education, 27(4), 285-99.

Hickey, M. (2015). Learning from the experts: A study of free-improvisation in university settings. Journal of Research in Music Education, 62(4), 425-45.

Higgins, L., \& Mantie, R. (2013). Improvisation as ability, culture, and experience. Music, Educators Journal, 100(2), 38-44.

Hutto, D., \& Myin, E. (2012). Radicalizing enactivism: Basic minds without content. Cambridge, MA: MIT Press.

Imada, T. (2012). The grain of the music: Does music education "mean" something in Japan? In W. Bowman \& L. Frega (Eds.), The Oxford handbook of philosophy in music education (pp. 147-62). Oxford: Oxford University Press.

Ihde, D. (1976). Listening and voice: A phenomenology of sound. Athens: Ohio University Press.

Ihde, D. (1977). Experimental phenomenology: An introduction. New York: G. P. Putnam's Sons.

Iyer, V. (2002). Embodied mind, situated cognition, and expressive microtiming in AfricanAmerican music. Music Perception, 19(3), 387-414.

Iyer, V. (2004). Exploding the narrative in jazz improvisation. In R. G. O’Meally, B. H. Edwards, \& F. J. Griffin (Eds.), Uptown conversation: The new jazz studies (pp. 393-403). New York: Columbia University Press.

Iyer, V. (2008). On improvisation, temporality, and embodied experience. In P. Miller (Ed.), Sound unbound (pp. 273-93). Cambridge, MA: MIT Press.

Johnson, M. (2007). The meaning of the body: Aesthetics of human understanding. Chicago: University of Chicago Press. 


\section{Improvisation, Enaction, and Self-Assessment}

Kanellopoulos, P. A. (2011). Freedom and responsibility: The aesthetics of free musical improvisation and its educational implications-a view from Bakhtin. Philosophy of Music Education Review, 19(2), 113-35.

Kincheloe, J. L. (2003). Critical ontology: Visions of selfhood and curriculum. Journal of Curriculum Theorizing, 19(1), 47-64.

Kincheloe, J. L. (2008). Knowledge and critical pedagogy: An introduction. London: Springer.

Kincheloe, J. L., \& Berry, K. (2004). Rigour and complexity in educational research: Conceptualizing the bricolage. New York: Open University Press.

(p. 342) Kincheloe, J. L., Steinberg, S., \& Villaverde, L. (1999). Rethinking intelligence: Confronting psychological assumptions about teaching and learning. New York: Routledge.

Konowitz, B. (1973). Music improvisation as a classroom method: A new approach to teaching music. New York: Alfred Publishing.

Krueger, J. (2011a). Doing things with music. Phenomenology and the Cognitive Sciences, 10(1), 1-22.

Krueger, J. (2011b). Enacting musical content. In R. Manzotti (Ed.), Situated aesthetics: Art beyond the skin (pp. 63-85). Exeter, UK: Imprint Academic.

Krueger, J. (2013). Empathy, enaction, and shared musical experience. In T. Cochrane, B. Fantini, \& K. Scherer (Eds.), The emotional power of music: Multidisciplinary perspectives on musical expression, arousal, and social control (pp. 177-96). Oxford: Oxford University Press.

Krueger, J. (2014). Affordances and the musically extended mind. Frontiers in Psychology, 4, 1003. doi:10.3389/fpsyg.2013.01003

Lajoie, S. (2005). Extending the scaffolding metaphor. Instructional Science, 33(5-6), 54157.

Laroche, J., \& Kaddouch, I. (2015). Spontaneous preferences and core tastes: embodied musical personality and dynamics of interaction in a pedagogical method of improvisation. Frontiers in Psychology, 6, 522. doi:10.3389/fpsyg.2015.00522

Lasker, H. (1971). Teaching creative music in secondary schools. Boston: Allyn and Bacon. Lawrence, I. (1978). Composers and the nature of music education. London: Scolar Press.

Lewis, G. E. (2004). Improvised music after 1950: Afrological and Eurological perspectives. In D. Fischlin \& A. Heble (Eds.), The other side of nowhere: Jazz, improvisation, and communities in dialogue (pp. 131-62). Middletown, CT: Wesleyan University Press. 
Lewis, G. E. (2007). Improvisation and pedagogy: Background and focus of inquiry. Critical Studies in Improvisation, 3(2), 1-5. Retrieved from http://www.criticalimprov.com/ article/view/412/659

Lewis, G. E. (2009a). The condition of improvisation. Keynote address, International Society for Improvised Music, Santa Cruz, New Mexico.

Lewis, G. E. (2009b). A power stronger than itself: The AACM and American experimental music. Chicago: University of Chicago Press.

Lewis, G. E., \& Piekut, B. (2016). The Oxford handbook of critical improvisation studies (Vol. 1). Oxford: Oxford University Press.

Litweiler, J. (1990). The freedom principle: Jazz after 1958. New York: Da Capo Press.

MacDonald, R., Wilson, G., \& Miell, D. (2011). Improvisation as a creative process within contemporary music. In D. Hargreaves, D. Miell, \& R. MacDonald (Eds.), Musical imaginations: Multidisciplinary perspectives on creativity, performance and perception (pp. 24256). Oxford: Oxford University Press.

Marsh, K. (1995). Children's singing games: composition in the playground. Research Studies in Music Education, 8(2), 80-93.

Matyja, J., \& Schiavio, A. (2013). Enactive music cognition. Constructivist Foundations, 8, 351-57.

McGann, M., De Jaegher, H., \& Di Paolo, E. (2013). Enaction and psychology. Review of General Psychology, 17(2), 203-9.

McPherson, M. J., Lopez-Gonzalez, M., Rankin, S. K., \& Limb, C. J. (2014). The role of emotion in musical improvisation: An analysis of structural features. PLoS ONE, 9, e105144. doi:10.1371/journal.pone.0105144

MENC, National Commission on Instruction. (1974). The school music program: Description \& standards. Reston, VA: MENC.

(p. 343) Miller, D., \& Iyer, V. (2010). Improvising digital culture: A conversation. Critical Studies in Improvisation, 5(1), 1-10.

Monga, V. (Producer \& Director). (2012). Black February: Music is an open door [Motion picture]. United States: Studio unavailable.

Monson, I. (1996). Saying something: Jazz improvisation and interaction. Chicago: University of Chicago Press.

Monson, I. (2007). Freedom sounds: Civil rights call out to jazz and Africa. New York: Oxford University Press. 
Moorhead, G. E., \& Pond, D. (1941/1978). Music for young children. Santa Barbara, CA: Pillsbury Foundation for the Advancement of Music Education. (Reprint from the 19411951 editions.)

Musical Futures. (2008). Musical Futures curriculum. Retrieved from http:// www.musicalfutures.org.uk/mfInWords.html

Nachmanovitch, S. (1990). Free play: Improvisation in life and art. New York: Tarcher/ Perigee.

Nettl, B. (1974). Thoughts on improvisation: A comparative approach. Musical Quarterly, 60(1), 1-19.

Nettl, B. (1998). Introduction. In B. Nettl (Ed.), In the course of performance (pp. 1-26). Chicago: University of Chicago Press.

Nettl, B., \& Russell, M. (Eds.). (1998). In the course of performance: Studies in the world of musical improvisation. Chicago: University of Chicago Press.

Nöe, A. (2006). Action in perception. Cambridge, MA: MIT Press.

O’Neill, S. A. (2010). On becoming a music learner: Understanding relationships that foster growth. Canadian Music Educator, 51(3), 26-28.

O'Neill, S. A. (2014). Mind the gap: Transforming music engagement through learner-centered informal music learning. The Recorder: Journal of the Ontario Music Educators' Association, 56(2), 18-22.

Oyama, S. (2000). The ontogeny of information (2nd ed.). Durham, NC: Duke University Press.

Paynter, J. (1992). Sound and structure. New York: Cambridge University Press.

Pinker, S. (2009). How the mind works. New York: Norton.

Pressing, J. (1988). Improvisations, methods and models. In J. Sloboda (Ed.), Generative processes in music (pp. 129-78). New York: Clarendon Press.

Pressing, J. (1998). Psychological constraints on improvisational expertise and skill. In B. Nettl (Ed.), In the course of performance (pp. 47-67). Chicago: University of Chicago Press.

Price, D. (2006). Personalizing music learning. London: Paul Hamlyn Foundation.

Reddy, V., Markova, G., \& Wallot, S. (2013). Anticipatory adjustments to being picked up in infancy. PLoS ONE, 8(6), 1-9.

Regelski, T. A. (2002). On "methodolatry" and music teaching as critical and reflective praxis. Philosophy of Music Education Review, 10(2), 102-23. 
Reybrouck, M. (2001). Biological roots of musical epistemology: Functional cycles, umwelt, and enactive listening. Semiotica, 134(1-4), 599-633.

Reybrouck, M. (2005). A biosemiotic and ecological approach to music cognition: event perception between auditory listening and cognitive economy. Axiomathes, 15(2), 229-66.

Reybrouck, M. (2006). Music cognition and the bodily approach: Musical instruments as tools for musical semantics. Contemporary Music Review, 25(1/2), 59-68.

Rodriguez, C. X. (2004). Popular music in music education: Toward a new conception of musicality. In C. X. Rodriguez (Ed.), Bridging the gap: Popular music and music education (pp. 13-28). Carlos Reston, VA: MENC.

(p. 344) Roholt, T. C. (2014). Groove: A phenomenology of rhythmic nuance. New York: Bloomsbury.

Sarath, E. W. (1996). A new look at improvisation. Journal of Music Theory, 40, 1-38.

Sarath, E. W. (2013). Improvisation, creativity, and consciousness: Jazz as integral template for music, education, and society. Albany: State University of New York Press.

Sawyer, K. R. (1996). The semiotics of improvisation: The pragmatics of musical and verbal performance. Semiotica, 108(3-4), 269-306.

Sawyer, K. R. (2003). Group creativity: Music, theater, collaboration. Mahwah, NJ: Erlbaum.

Sawyer, K. R. (Ed.). (2006). The Cambridge handbook of the learning sciences. New York: Cambridge University Press.

Sawyer, K. R. (2007). Improvisation and teaching. Critical Studies in Improvisation, 2(2). Retrieved from http://www.criticalimprov.com/article/view/380/626

Schafer, R. M. (1986). The thinking ear: Complete writings on music education. Bancroft, ON: Arcana Editions.

Schafer, R. M. (1994). The soundscape: Our sonic environment and the tuning of the world. Rochester, VT: Destiny Books.

Schiavio, A., van der Schyff, D., Cespedes-Guevara, J., \& Reybrouck, M. (2016). Enacting musical emotions: Enaction, dynamic systems and the embodied mind. Phenomenology and the Cognitive Sciences, 16(5), 785-809. doi:10.1007/s11097-016-9477-8

Schön, D. A. (1983). The reflective practitioner: How professionals think in action. London: Temple Smith.

Service, V. (1984). Maternal styles and communicative development. In A. Lock \& E. Fisher (Eds.), Language development (pp. 132-40). London: Croom Elm. 
Sessions, R. (1941). The composer and his message. In A. Centeno (Ed.), The intent of the artist (pp. 101-34). Princeton, NJ: Princeton University Press.

Silverman, M. (2012). Virtue ethics, care ethics, and "the good life of teaching." Action, Criticism, and Theory for Music Education, 11(2), 96-122.

Szekely, M. (2012). Musical education: From identity to becoming. In W. D. Bowman \& A. L. Frega (Eds.), The Oxford handbook of philosophy in music education (pp. 163-79). New York: Oxford University Press.

Small, C. (1998). Musicking: The meaning of performing and listening. Middletown, CT: Wesleyan University Press.

Sterne, J. (2012). The sound studies reader. New York: Routledge.

Stevens, J. (2007). Search and reflect: A music workshop handbook. Middlesex, UK: Rockschool.

Stewart, J., Gapenne, O., \& Di Paolo, E. A. (Eds.). (2010). Enaction: Toward a new paradigm for cognitive science. Cambridge, MA: MIT Press.

Sudnow, D. (1978). Ways of the hand: The organization of improvised conduct. Cambridge, MA: Harvard University Press.

Swanwick, K., \& Tillman, J. (1986). The sequence of musical development: A study of children's compositions. British Journal of Music Education, 3, 305-39.

Tarasti, E. (1993). From Mastersingers to Bororo Indians: On the semiosis of improvisation. In T. Bram (Ed.), Proceedings from the Congress on Improvisation (pp. 62-81).

Lucerne, Switzerland.

Thompson, E. (2007). Mind in life: Biology, phenomenology and the sciences of mind. Cambridge, MA: Harvard University Press.

Toop, D. (2016). Into the maelstrom: Music, improvisation and the dream of freedom. New York: Bloomsbury.

Trevarthen, C. (2002). Origins of musical identity: Evidence from infancy for musical social awareness. In R. A. R. MacDonald, D. J. Hargreaves, \& D. Miell (Eds.), Musical identities (pp. 21-38). Oxford: Oxford University Press.

(p. 345) Urban, P. (2014). Toward an expansion of an enactive ethics with the help of care ethics. Frontiers in Psychology, 5, 1-3. doi:10.3389/fpsyg.2014.01354

van der Schyff, D. (2013). The free improvisation game: Performing John Zorn's "Cobra”. The Journal of Research in Music Performance (Spring, 2013). https://

ejournals.lib.vt.edu/JRMP/article/view/726. 
van der Schyff, D. (2015a). Music as a manifestation of life: Exploring enactivism and the "Eastern perspective" for music education. Frontiers in Psychology, 6, 345. doi:10.3389/ fpsyg.2015.00345

van der Schyff, D. (2015b). Praxial music education and the ontological perspective: An enactivist response to Music Matters 2. Action, Criticism and Theory for Music Education, 14(3), 75-105.

van der Schyff, D. (2016). From Necker cubes to polyrhythms: Fostering a phenomenological attitude in music education. Phenomenology and Practice, 10(1), 4-24.

van der Schyff, D., Schiavio, A., \& Elliott, D. J. (2016). Critical ontology for an enactive music pedagogy. Action, Theory and Criticism for Music Education, 15(5), 81-121.

Varela, F. J., Thompson, E., \& Rosch, E. (1991). The embodied mind: Cognitive science and human experience. Cambridge, MA: MIT Press.

Walton, A., Richardson, M. J., \& Chemero, A. (2014). Self-organization and semiosis in jazz improvisation. International Journal of Signs and Semiotic Systems, 3(2), 12-25.

Walton, A., Richardson, M. J., Langland-Hassan, P., \& Chemero, A. (2015). Improvisation and the self-organization of multiple musical bodies. Frontiers in Psychology, 1(6). doi: 10.3389/fpsyg.2015.00313

Watson, B. (2013). Derek Bailey and the story of free improvisation. London: Verso.

Weber, A., \& Varela, F. J. (2002). Life after Kant: Natural purposes and the autopoietic foundations of biological individuality. Phenomenology and the Cognitive Sciences, 1(2), 97-125.

Weil, D. (2001). Whose world, which economic classes, and what standards? In J. L. Kincheloe \& D. K. Weil (Eds.), Standards and schooling in the United States: An encyclopedia (Vol. 1, pp. 505-33). Denver, CO: ABC-CLIO.

Whitehead, K. (2000). New Dutch swing. New York: Billboard Books.

Wopereis, I. G. J. H., Stoyanov, S., Kirschner, P. A., \& Van Merriënboer, J. J. G. (2013). What makes a good musical improviser? An expert view on improvisational expertise. Psychomusicology, 23, 222-35. doi:10.1037/pmu0000021

Wright, R., \& Kanellopoulos, P. A. (2010). Informal music learning, improvisation and teacher education. British Journal of Music Education, 27, 71-87.

Zorn, J. (2004). The game pieces. In C. Cox \& D. Warner (Eds.), Audio culture: Readings in modern music (pp. 196-200). New York: Continuum. 


\section{Notes:}

(1.) It should be noted that improvisational practice remains an important part of organ performance and pedagogy.

(2.) While several studies have explored how the two processes differ (Sarath, 1996; Azzara, 2002), it has been suggested that composition and improvisation should no longer be understood as opposites, but rather as mutually reinforcing aspects of the creative musical process (Biasutti, 2015; Marsh, 1995; Sessions, 1941). Indeed, in Swanwick and Tillman's (1986) studies of how young children "compose" music, improvisation and composition are essentially indistinguishable. And likewise, as Burnard (2000) writes, "our aim as music educators should be to facilitate a form of music education that focuses on genuine experiences of children being improvisers and composers rather than acting out a pre-defined model" (p. 21).

(3.) See, for example, the K-4 improvisation assessment strategy in MENC (1996, p. 39; also in Hickey, 2009).

(4.) Such codifying tendencies have also dominated small group pedagogy. As Bailey (1993) writes of bebop: "The mechanics of this particular style-its somewhat stylistic rigidity, its susceptibility to formulated method - created a field day for the educators. [...] It has proved to be one style of improvising which can be easily taught" (p. 49).

(5.) Perhaps a loose distinction should be made here between "free improvisation" as an open-ended pedagogical approach and "free improvisation" as a specific musical movement that developed in Europe in the mid-twentieth century.

(6.) In the course of its development, enactivism has produced a number of schools of thought, with each positing contrasting perspectives that originate in a shared group of basic principles (Hutto \& Myin, 2012). As space does not permit a full treatment of each of these perspectives, the brief outline I offer here draws mostly on the original autopoietic approach introduced in the early 1990s by Varela et al. (1991), and that has recently been updated by Evan Thompson (2007) and others (see Stewart et al., 2010).

(7.) As Varela et al. (1991) elaborate: "There is always a next step for the system in its perceptually guided action [...] the actions of the system are always directed toward situations that have yet to become actual. Thus cognition as embodied action both poses the problems and specifies those paths that must be tread or laid down for their solution" ( $p$. 205).

(8.) For an interesting supporting discussion that considers musical improvisation in the context of the enactive biological principles discussed here, see Walton, Richardson, \& Chemero (2014).

(9.) However, it is important to understand that such normative or institutionalized ways of thinking and doing also emerge from historical processes of human enactment and thus need not be understood as entirely fixed (De Jaegher, 2013). 
(10.) Developments in musical semiotics may also offer useful ways of exploring and discussing how communication develops in such contexts. Here a range of recent research has drawn on embodied-enactive cognition and dynamical systems theory to explain how sonic, kinesthetic, and ecological factors contribute to the enactment of meaningful signals in improvising ensembles (Iyer, 2002, 2004, 2008; Reybrouck, 2001, 2005; Sawyer, 1996; Walton et al., 2014). Although some of this literature involves complex terminology and detailed empirical studies, it is certainly not beyond the ability of a dedicated educator to draw out and introduce the key areas of inquiry for use in collaborative assessment.

(11.) Here the introduction of sound studies into the music curriculum becomes important (Sterne, 2012). R. M. Schafer's $(1986,1994)$ writings on music education and soundscape studies offer an excellent starting place.

(12.) By now it should be apparent that from a 4E perspective distinctions between reflection and self-assessment necessarily become less clearly defined. Reflection is sometimes associated with the goal of "knowing," while the goal of self-assessment is "growing." The former involves "a personal process that can deepen one's understanding of self and can lead to significant discoveries or insight," while the latter is often understood as "a process that involves establishing strengths, improvements, and insights based on predetermined performance criteria" (see Desjarlais \& Smith, 2011, p. 3). However, because the conception of improvisation discussed here goes beyond such "predetermined criteria," a 4E understanding of what self-assessment entails will necessarily involve an overlapping or reciprocal relationship with critical reflection and with the creative praxis of the larger musical ecology.

(13.) For an interesting approach to the analysis of recordings of free improvisation, see Canonne and Garnier (2012).

(14.) Readers are especially encouraged to explore the four-part documentary series On The Edge, hosted by improvising guitarist Derek Bailey and presented by Channel 4 (UK).

(15.) Of course there is also a range of possibilities for exploring improvisation across a range of non-Western traditions (Nettl, 1974; Nettl \& Russell, 1998).

(16.) Elsewhere (van der Schyff, 2013) I discuss a rehearsal and performance of "Cobra" in detail and briefly consider my experience developing it in an educational context.

\section{Dylan van der Schyff}

Dylan van der Schyff is a postdoctoral research fellow in the Faculty of Music at the University of Oxford. His scholarship draws on recent developments in embodied cognitive science to explore questions related to how and why music is meaningful for human beings; a special focus is given to developing possibilities for thought and action in practical areas such as performance and music education. His published work appears in journals that cover a broad spectrum of fields in the sciences and humanities, including, Frontiers in Neuroscience; Phenomenology and Practice; Psy- 
chomusicology: Music Mind and Brain; Phenomenology and the Cognitive Sciences; Frontiers in Psychology; Action, Criticism, and Theory for Music Education; and Interference: A Journal of Audio Culture. Van der Schyff is also an experienced music educator and performer, appearing on well over one hundred recordings that span the fields of jazz, free improvisation, experimental, and "new music." 